\title{
Is inhibition of kinase activity the only therapeutic strategy for LRRK2-associated Parkinson's disease?
}

\author{
lakov N Rudenko ${ }^{\dagger}$, Ruth $\mathrm{Chia}^{\dagger}$ and Mark R Cookson ${ }^{*}$
}

\begin{abstract}
Mutations in the leucine-rich repeat kinase 2 (LRRK2) gene are a common cause of familial Parkinson's disease (PD). Variation around the LRRK2 locus also contributes to the risk of sporadic PD. The LRRK2 protein contains a central catalytic region, and pathogenic mutations cluster in the Ras of complex protein $\mathrm{C}$ terminus of Ras of complex protein (mutations N1437H, R1441G/C and Y1699C) and kinase (G2019S and I2020T) domains. Much attention has been focused on the kinase domain, because kinase-dead versions of mutant LRRK2 are less toxic than kinase-active versions of the same proteins. Furthermore, kinase inhibitors may be able to mimic this effect in mouse models, although the currently tested inhibitors are not completely specific. In this review, we discuss the recent progress in the development of specific LRRK2 kinase inhibitors. We also discuss non-kinase-based therapeutic strategies for LRRK2-associated PD as it is possible that different approaches may be needed for different mutations.
\end{abstract}

\section{Introduction}

Parkinson's disease (PD) is a relatively common agerelated neurodegenerative disorder [1]. In the past few years, it has become recognized that there are singlegene disorders that are clinically and pathologically similar to sporadic PD [2]. Furthermore, a series of genomewide association studies (GWAS) have identified a number of loci that contribute to the risk for sporadic PD [3-8].

\footnotetext{
* Correspondence: cookson@mail.nih.gov

† Contributed equally

Cell Biology and Gene Expression Section, Laboratory of Neurogenetics, National Institute on Aging, National Institutes of Health, 35 Convent Drive, Room 1A-116, Bethesda, MD 20892-3707, USA
}

The most common single genetic cause of autosomal dominant PD is missense mutations in the leucine-rich repeat kinase 2 (LRRK2) gene $[9,10]$. Variation around the $L R R K 2$ locus also appears to be a risk factor for sporadic PD [4,11]. Many single-nucleotide substitutions have been reported in the LRRK2 gene, but only six have been verified to be pathogenic $[12,13]$. These mutations are located predominantly in the enzymatic domains of LRRK2, including the kinase domain for which LRRK2 is named. There is a particularly common mutation, G2019S, in the kinase domain that increases the kinase activity of the protein (reviewed in [14]).

For many LRRK2 cases, the clinical signs in affected carriers of the mutation are remarkably similar to idiopathic PD and include tremor, rigidity, postural instability and bradykinesia [15-17]. There is some variation, as individual patients may have developed amyotrophy [18], whereas in one of the first described families, there is more frequent gait disturbance and less frequent tremor compared to sporadic PD [19]. However, the general picture is that LRRK2 causes a disease that overlaps substantially with sporadic PD.

Because LRRK2 is a kinase, it has been suggested that targeting kinase activity might be a therapeutic strategy for familial PD. Furthermore, because LRRK2-related PD and sporadic PD are clinically similar, it might be extrapolated that targeting kinase activity might also be helpful in treating the more common idiopathic form of the disease.

In this review, we discuss the evidence underlying the idea that LRRK2's kinase activity might be modified to protect against $\mathrm{PD}$. We also focus on the alternative idea that there are other aspects of LRRK2 function that might equally be addressed therapeutically. To understand these two ideas, it is important first to identify the mutations in LRRK2 that are associated with PD and how these affect protein function.

\section{Ciomed Central}




\section{Pathogenic mutations in PD affect protein function}

LRRK2 has a complex multidomain structure. The central part of the protein contains three independent domains. The Ras of complex protein (ROC) and $\mathrm{C}$ terminus of ROC (COR) bidomain is characteristic of the ROCO family of proteins [20]. The ROC domain binds GTP, and the COR domain is thought to be a regulator of ROC GTPase activity [21]. LRRK2 is an active protein kinase [22,23], although the true physiological target of this kinase activity has not been resolved.

It has been proposed that the ROC-COR and kinase domains of LRRK2 may control each other. Mutations in the ROC domain that prevent GTP binding are kinase-inactive, leading to the suggestion that the GTPase activity regulates kinase activity (reviewed in [14]). Recent evidence presented by two independent groups, however, showed that kinase activity of LRRK2 is not increased by adding GTP as would be predicted with the use of this model $[20,24]$. An alternative interpretation is that the GTP-binding mutants disrupt or destabilize the ROC domain, resulting in a loss of kinase activity as a secondary output. It is possible that instead the kinase domain of LRRK2 regulates the ROC domain and thus that the kinase domain is the modulator of activity rather than the output of the protein $[12,25]$. However, whether this regulation actually happens in vivo is unknown [14]. Currently, it is thought that there is some form of regulation between the enzymatic domains of LRRK2, although the details of the mechanisms still need to be resolved.

The flanking ankyrin/heat repeats and leucine-rich repeat (LRR) domains at the $\mathrm{N}$ terminus and WD40 domain at the $\mathrm{C}$ terminus are thought to participate in protein-protein interactions. However, the physiological role or identification of interactors of these domains and how these domains dictate LRRK2 function remain unclear. There may be a role for some of these regions in the control of LRRK2 kinase activity, as the removal of sequences from the $\mathrm{C}$ terminus has been shown to abolish the phosphorylation ability of LRRK2 [26,27]. Overall, the available data suggest that LRRK2 is a protein that has kinase activity, binds GTP and could play a scaffolding role via its protein-protein interaction domains.

Several groups have shown that the G2091S mutation augments in vitro kinase activity of LRRK2 by two- to fourfold [22,23,26,28-35]. This might suggest that all mutants have a simple gain of kinase function mechanism. I2020T is located at the next residue of LRRK2 as G2019S, but it has either a modest increase [36,37] or a reduced [26] or no effect [35] on kinase activity levels compared to wild type (WT). The simplest interpretation is that the I2020T mutation does not increase kinase activity, at least in the way it is currently assayed, which contrasts with G2019S. Therefore, whether all mutations, even those in the kinase domain, increase the kinase activity of LRRK2 is uncertain. Some variants seem to consistently decrease kinase activity, including the G2385R variant [26] that is a genetic risk factor for PD in some populations. Therefore, these variants would seem to be pathogenic by a non-kinase-dependent mechanism.

Another group of LRRK2 mutations is clustered in the ROC-COR bidomain. The R1441 position in the ROC/ GTPase is mutated to cysteine, glycine or histidine (that is, $\mathrm{R} 1441 \mathrm{C} / \mathrm{G} / \mathrm{H})$ in families with PD [10,38-42]. Several families who have a Y1699C mutation in the adjacent COR domain have been described $[10,43]$. A recent addition to this mutation cluster is $\mathrm{N} 1437 \mathrm{H}$, which was found in a large Norwegian family with autosomal dominant parkinsonism [13]. Overall, the balance of the evidence is that R1441 and Y1699 mutations raise the kinase activity of LRRK2 only very modestly. In contrast, the R1441C/G [44-46] and Y1699C mutations consistently lower GTPase activity [46]. The GTPase activity for $\mathrm{N} 1437 \mathrm{H}$ has not been determined, but it has been shown that this mutant has increased GTP binding [13], which is consistent with lower GTPase activity. The reported GTP-binding capacity of R1441C/G and $\mathrm{Y} 1699 \mathrm{C}$ is less consistent, with some reports of an increase and others finding no change in GTP binding $[45,47,48]$. These effects are probably related, as it has been proposed that the ROC and COR domains may interact with each other. R144C destabilizes the ROC domain [49], whereas Y1699C substitution strengthens the intramolecular ROC-COR interaction [46]. Although the precise details still need to be worked out, this suggests that interactions in the ROC-COR bidomain are important in controlling the GTPase activity of LRRK2 and that this may be dysregulated by mutation.

Although the molecular mechanisms by which mutations affect LRRK2 seem to differ, there are phenotypes reported at the cellular level that appear to be consistent between mutations. At least under the conditions of high-level expression of LRRK2 in vitro, mutant forms of LRRK2 are acutely toxic $[23,27,29,47,50]$. For G2019S LRRK2, there is evidence that cell death also occurs in vivo with viral vector-mediated expression [51,52].

In cultured neurons, neurite shortening is also a rather consistent phenotype associated with mutant LRRK2, even in models where cell death is not apparent [28,53-58]. Importantly, all mutations tested to date have one or both of these effects in cells, suggesting that these are common outputs of the same signaling pathways that are affected by mutant LRRK2.

Although not all mutations the have been found to increase kinase activity of LRRK2 using assays that have been tried to date, kinase-inactive versions of the same 
mutations are not toxic $[23,29,55]$. Furthermore, a kinase-dead G2019S is not toxic to dopaminergic (DA) neurons in vivo [51]. This implies that pathogenesis is dependent on having functional kinase activity. This has led to the idea that the enzyme activity of LRRK2 might be targeted in developing a new therapeutic drug for patients with PD.

\section{Therapeutic strategies for LRRK2-associated Parkinson's disease}

The facts that G2019S, the most frequent mutation in LRRK2-associated PD, causes augmentation of LRRK2 kinase activity and that cytotoxicity is dependent on kinase activity lead to the suggestion that inhibition of LRRK2 kinase activity might be therapeutically beneficial. Given the complexity of the LRRK2 molecule, however, it is also possible that there are other aspects of function that might be targeted. Herein we discuss the possibilities of LRRK2 therapeutic agents from the standpoint of kinase inhibition, GTP binding inhibition and other possible alternative avenues for LRRK2-associated PD treatment (Figure 1).

\section{Targeting LRRK2 kinase and GTPase activity}

One approach to manipulating LRRK2 is to develop kinase inhibitors, and this is usually accomplished by making compounds that compete for ATP in the ATPbinding pocket of LRRK2. The selectivity of most kinase inhibitors is therefore incomplete, as most will inhibit other kinases depending on the amount of structural similarity in this region of the kinase. As might be expected, several known kinase inhibitors also inhibit LRRK2, but all have some nonspecific effects [51,59-61]. Because nonspecific inhibition of other kinases can lead to ambiguous results, the ideal compound with which to examine LRRK2 function and dysfunction would have maximum selectivity. Two recently reported compounds, LRRK2-IN1 and CZC-25146, have better selectivity than other kinases for LRRK2 [62,63].

These tools are being used in the laboratory to probe LRRK2 function because they are cell-permeable, but study of them probably will not proceed to clinical trials as they do not accumulate in the brain. Experimentally, one can infuse inhibitors through the cerebral ventricles [51], but this may not be helpful for humans. Therefore, one of the key developments needed in the field to test whether kinase inhibition could work in LRRK2 patients is to develop specific and potent LRRK2 inhibitors, preferably ones that can be given orally (discussed in From bench to bedside: clinical trials and future prospects).

However, there is some data that suggests that chemical inhibition of LRRK2 may not give the same results

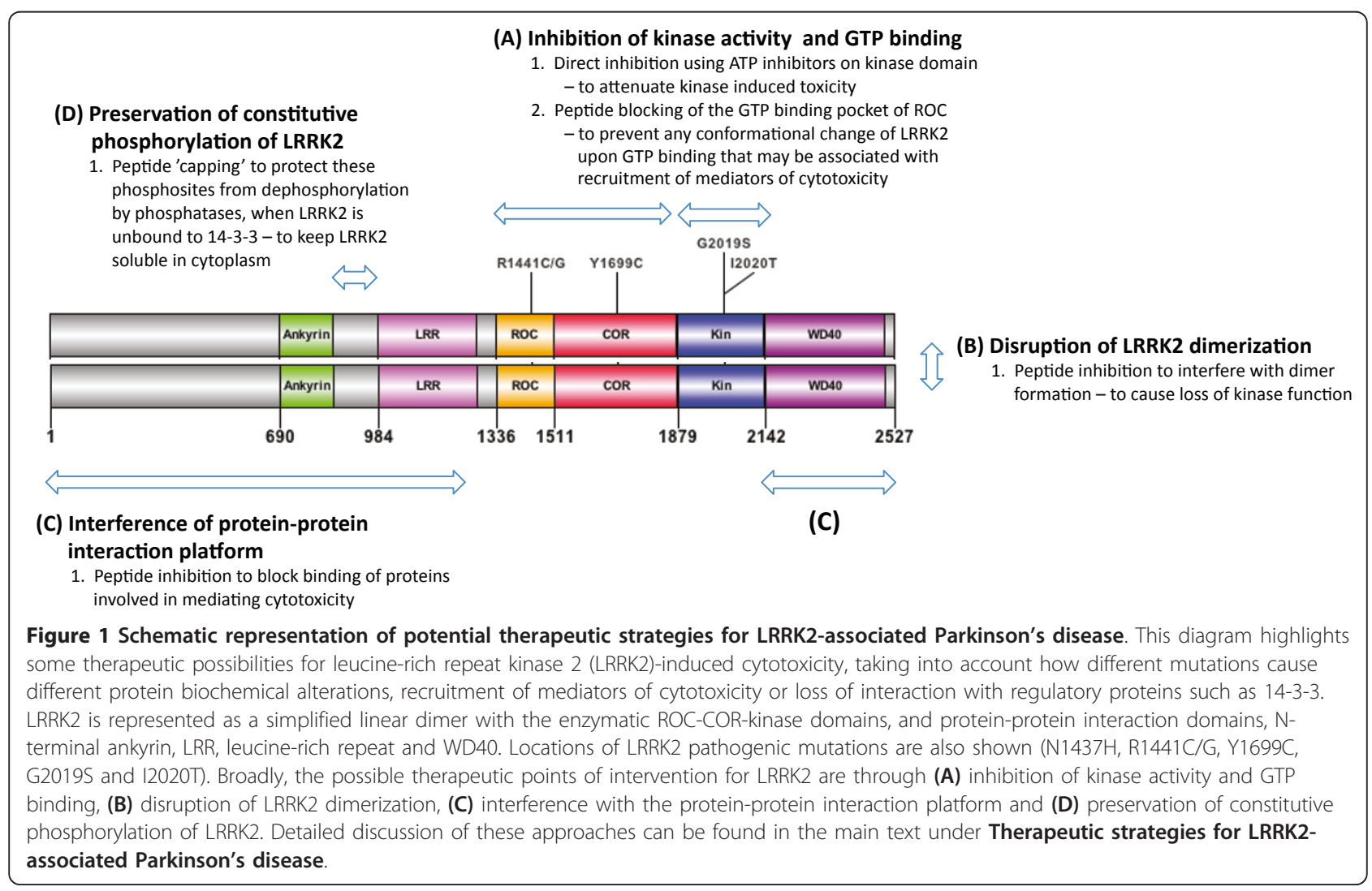


as expressing a genetically modified kinase-dead protein. Application of kinase inhibitors to cells expressing LRRK2 causes loss of phosphorylation at S910 and S935, located at the $\mathrm{N}$ terminus of LRR. This is further associated with the loss of binding to 14-3-3 protein and rearrangement of LRRK2 into filamentous structures. In contrast, kinase-dead LRRK2 retains phosphorylation and 14-3-3 binding and remains cytoplasmic [35]. Therefore, at least in these cellular assays, kinase-dead and kinase-inhibited LRRK2 are not the same.

Worryingly, some pathogenic LRRK2 mutants (R1441C/G, Y1699C and I2020T, but not G2019S) abolished 14-3-3 binding and loss of LRRK2 constitutive phosphorylation. Additionally, these mutants have more LRRK2 inclusion bodies formed in the cytoplasm compared to WT LRRK2 bound to 14-3-3 [35]. Therefore, one must ask if kinase inhibitors might push LRRK2 toward rather than away from a pathogenic form. If this is true, we cannot yet predict the effects of kinase inhibitors and whether these would be the same as those of kinase-dead LRRK2. Although there are data supporting kinase inhibitors preventing neuronal toxicity $[51,60]$, which might more logically be a predictor of therapeutic benefit in patients, experiments performed to date have been done with the less selective agents. Therefore, the data need to be reassessed with more potent and selective kinase inhibitors.

It therefore seems appropriate to think about other approaches for LRRK2 other than kinase inhibition using competitive ATP inhibitors. Kinases often participate in ordered signaling cascades, and thus upstream and downstream effectors of LRRK2 are also attractive targets for pharmacological therapy for patients with PD. Modulating the activity of proteins involved in these cascades could compensate for the impairment of LRRK2 function caused by mutations. For example, as shown in LRRK2 Drosophila models, co-overexpression of 4E-BP on the G2019S-mutant background prevented neurotoxicity [30]. $4 \mathrm{E}-\mathrm{BP}$ is a negative regulator involved in the regulation of translation via binding of eukaryotic initiation factor 4E (eIF4E). Interestingly, mutations in EIF4G1 which bind to eIF4E are also associated with dominantly inherited parkinsonism [64]. Phosphorylation of 4E-BP by LRRK2 causes release of eIF4E from being bound to $4 \mathrm{E}-\mathrm{BP}$. Because $4 \mathrm{E}-\mathrm{BP}$ is also implicated in the mammalian target of rapamycin pathway, it may be possible to regulate the LRRK2induced effects of 4E-BP by using rapamycin. Tain et al. showed this to be a plausible approach in Drosophila models, in which they showed that treatment with rapamycin prevented DA neuronal loss [65]. However, the effect of LRRK2 on 4E-BP has yet to be demonstrated in LRRK2 mammalian models.
One other possible target is modulation of LRRK2 GTPase activity. Binding of GTP to LRRK2 could change its conformation, which in turn could mediate interaction with different proteins. GTPases usually cycle between GDP- and GTP-bound states with different affinities for heterologous interactors. For LRRK2, the data on R1441C and Y1699C having lower GTPase activity suggest that the GTP-bound form is associated with disease. Thus blocking the GTP-binding pocket of ROC or stimulation of GTPase activity to limit a pathogenic interaction could be a potential therapeutic target for LRRK2-associated PD [14]. These might be particularly helpful for R1441- and Y1699-mutant LRRK2, but to date no such tools are available that could achieve this goal.

\section{Strategies based outside the enzymatic regions}

Because LRRK2 has many protein-protein interaction domains with no catalytic activity, it is possible that LRRK2 is a scaffold, serving as a platform on which different proteins assemble to perform a specific function. These domains may play a role in mediating the cytotoxicity induced by LRRK2 kinase activity. It has been shown that deletion of $\mathrm{N}$-terminal LRR portion or WD40 of G2019S and/or R1441C rescued LRRK2induced toxicity in neuronal cells $[27,50]$. This may be a point of therapeutic intervention by means of peptide inhibition in blocking the binding of proteins involved in mediating LRRK2-induced cytotoxicity as has been done for other globular proteins that interact [66].

Because the kinase activity of LRRK2 is dependent on its dimerization, a way to inhibit kinase activity of LRRK2 selectively could be to disrupt dimeric LRRK 2 . This could be achieved by using inhibitory peptides to interfere with protein folding or dimer formation. This has been demonstrated to be a successful approach in HIV studies in which an inhibitory peptide was used to inhibit the folding of the HIV-1 protease, an important enzyme in the viral life cycle, thereby inhibiting the life cycle of the virus and controlling AIDS [67]. This therapeutic strategy could be useful for the Y1699C LRRK2 mutant, which has abnormally increased strength of interaction between the ROC and COR domains.

As discussed in Targeting LRRK2 kinase and GTPase activity, some mutant forms of LRRK2 lose the ability to bind 14-3-3 proteins. The mechanisms underlying the loss of constitutive phosphorylation and 14-3-3 binding are not known, but it is possible that the functional effect of these changes is to make LRRK2 less soluble. From this point of view, a possible intervention is to design a peptide that could serve as a "cap" in protecting these sites, when unbound to 14-3-3, from being dephosphorylated by phosphatases. This might more 
accurately mimic what happens with kinase-dead LRRK2, which appears not to be toxic in model systems.

\section{From bench to bedside: clinical trials and future prospects}

Given the number of potential ways in which to interfere with LRRK2 dysfunction, it is rather early to discuss which drugs might be best developed to treat LRRK2related PD. There are some obvious issues that may stand in the way of the assessment and development of any drug, however, and it is worth discussing those issues with the goal of identifying key experiments in the field that should be performed with a long-term view that LRRK2 is "druggable."

With the development of any drug, the first step in assessing the efficacy of the drug is to test it in a suitable animal model. To date, there are more than ten mouse models carrying different $L R R K 2$-transgenes driven by different promoters (reviewed in [68]). Disappointingly, these models have not yet fully recapitulated all the clinical features seen in a PD patient. Although some DA neuronal death is observed in some of these models, the loss is not progressive and is rather limited with mild motor deficits. However, it has been reported that acute expression of mutant LRRK2 using viral vectors does replicate the DA neuronal cell loss seen in PD $[51,52]$. These models might be helpful in that they provide an opportunity to assess the acute application of inhibitors and might be the first level of testing novel agents with transgenic animals used for longer-term experiments, possibly using phenotypes other than DA neuronal cell loss if these can be shown to be reliable.

There are some general limitations in the development of all LRRK2 drugs. First, the potential therapeutic agent should be able to cross the blood-brain barrier (BBB). As discussed in Targeting LRRK2 kinase and GTPase activity, the most promising candidate assessed biochemically and in in vitro models is LRRK2-IN1. When tested in vivo, however, it was shown that LRRK2-IN1 does not affect the phosphorylation of S910 and S935 of LRRK2 in the mouse brain, but that it does abolish phosphorylation of S910/S935 in the kidneys, indicating that LRRK2-IN1 has poor BBB permeability [62]. These data suggest that future LRRK2 inhibitors need to have distinct properties to overcome the current lack of $\mathrm{BBB}$ penetration.

A corollary of this issue is that poor penetration of LRRK2 therapeutic agents across the BBB could cause an inadvertent accumulation of the agents in peripheral tissues. This could raise a potentially important toxicity problem, as, for example, it was recently shown that knocking down LRRK2 in mice had deteriorating effects on kidneys $[69,70]$. It would therefore be important to monitor the function of organs in which LRRK2 is highly expressed, particularly with regard to kidney and lung function. LRRK2 is also highly expressed in B cells, so immunological function should be assessed.

Another major problem in the development of LRRK2 drugs is the selectivity of the therapeutic agents. Even selective LRRK2 medications could have significant offtarget effects if used at high concentrations for an extended period. For example, it is well-established that no kinase inhibitor is exclusively selective to a single kinase [71]. If the concentration of the inhibitor is high enough, it could inhibit other structurally similar kinases and cause multiple side effects, a particular problem for extended use.

Assuming LRRK2 drugs were on hand, one difficult question would be when it would be most appropriate to start treatment. One the one hand, it would be logical to initiate prophylactic treatment in early adulthood in mutation carriers before the development of classic PD symptoms. In this case, appropriate therapy could potentially prevent or delay neuronal degeneration. One the other hand, mutations in the LRRK2 gene have incomplete penetrance and variable age at onset. Therefore, treatment of carriers could lead to long-term treatment of individuals who will not necessarily express the disease phenotype in their lifetimes, which presents both ethical and financial hurdles. This might then lead to the alternative view that any therapy should be restricted to individuals who have parkinsonism. It is also relevant that some of the motor aspects of PD are treatable, if imperfectly, by levodopa and by surgical approaches such as deep brain stimulation, so a LRRK2based strategy would have to have proven benefit compared to current treatments. Efficacy, measurement of the progression of PD symptoms and the safety of treatments over extended periods will have to be considered in the development of LRRK2 therapeutic regimens.

Another reasonable question is whether therapeutics based on LRRK2 could also be beneficial for sporadic PD. Ultimately, this question cannot be answered without a therapeutic agent in hand, and in all likelihood this agent would be one that has proven benefit in LRRK2 cases. If one had an appropriate compound, however, it would be possible to address the hypothesis whether LRRK2 PD and sporadic PD are mechanistically linked, so it is worth thinking about the probability that this hypothesis would be supported.

On the one hand, LRRK2 is a defined subset of PD where, as we have discussed, there is even some question whether all mutations work in the same way. This would suggest that LRRK2 mechanisms would be relevant only for LRRK2 PD, perhaps even for single mutations. On the other hand, LRRK2 cases are similar clinically, and sometimes pathologically, to sporadic PD; therefore, it is possible that the underlying mechanisms 
are similar. In further support of the idea that LRRK2 may play a role in sporadic $\mathrm{PD}$, there is a signal around the LRRK2 locus in GWAS in sporadic PD that is not accounted for by specific LRRK2 mutations [4]. Although the genetic basis of this association is unclear, one interpretation is that changes in the regulation of WT LRRK2 account for some of the lifetime risk of PD. By extrapolation, this would support the idea that LRRK2 is mechanistically linked to sporadic disease and would predict that LRRK2 therapies should be tried in idiopathic disease.

Recently, LRRK2 has been associated with an increased risk in some cancers, in particular melanoma [72,73]. PD patients with G2019S mutations have a threefold increased risk of developing melanoma before the onset of PD [72]. Whether a kinase inhibitor of LRRK2 would have any impact on cancer is very difficult to predict, but might be considered a potential extra target for drug development.

A biomarker of LRRK2 is needed to answer several of the above questions. Demonstration that a given drug has the desired effect in humans, that is, shows engagement of the target, will be crucial for deciding whether a given treatment has actually tested the underlying hypothesis. Furthermore, having a proximate biomarker for pathological LRRK2 activity would also be helpful in deciding whether the protein is involved in sporadic PD. What such a biomarker would look like is uncertain, although the action of LRRK2 kinase on a target protein is an obvious possibility. Development of these types of markers is eagerly awaited.

\section{Conclusion}

We have discussed some therapeutic intervention points for LRRK2 PD based on what is currently known about LRRK2 function and LRRK2-induced cytotoxicity. Although LRRK2 has been implicated in many cellular pathways, including apoptosis, cytoskeleton dynamics, protein translation and other cell signaling cascades, current data are predominantly descriptive and do not explain much of the underlying molecular mechanisms. The lack of this knowledge makes the development of drugs for LRRK2-associated PD difficult. Therefore, elucidation of the exact molecular mechanisms of the neurodegenerative processes caused by different mutations in LRRK2 would be very valuable in the design of LRRK2-specific therapeutics. Of all the proven pathogenic LRRK2 mutations, only G2019S substitution has augmented phosphorylation activity. Data on other mutants do not support significant changes in their kinase function, but they do indicate that other mutants cause toxicity. This fact allows us to propose that the therapeutic strategy for PD caused by different LRRK2 mutations could be diverse and may be dependent on the unique pathogenic mechanism conferred by each substitution.

\section{Abbreviations}

BBB: blood-brain barrier; COR: C terminus of Ras of complex protein; DA: dopaminergic; LRR: leucine-rich repeat; LRRK2: leucine-rich repeat kinase 2; PD: Parkinson's disease; ROC: Ras of complex protein.

\section{Acknowledgements}

This work was supported by the Intramural Research Program of the National Institute on Aging, National Institutes of Health.

\section{Authors' contributions}

INR, RC and MRC jointly wrote the manuscript and approved of the final manuscript.

\section{Competing interests}

The authors declare that they have no competing interests.

Received: 31 October 2011 Accepted: 23 February 2012

Published: 23 February 2012

\section{References}

1. Lees AJ, Hardy J, Revesz T: Parkinson's disease. Lancet 2009, 373:2055-2066, A published erratum appears in Lancet 2009, 374:684.

2. Vance JM, Ali S, Bradley WG, Singer C, Di Monte DA: Gene-environment interactions in Parkinson's disease and other forms of parkinsonism. Neurotoxicology 2010, 31:598-602.

3. Simón-Sánchez J, Schulte C, Bras JM, Sharma M, Gibbs JR, Berg D, PaisanRuiz C, Lichtner P, Scholz SW, Hernandez DG, Krüger R, Federoff M, Klein C, Goate A, Perlmutter J, Bonin M, Nalls MA, Illig T, Gieger C, Houlden H, Steffens M, Okun MS, Racette BA, Cookson MR, Foote KD, Fernandez HH, Traynor BJ, Schreiber S, Arepalli S, Zonozi R, et al: Genome-wide association study reveals genetic risk underlying Parkinson's disease. Nat Genet 2009, 41:1308-1312.

4. International Parkinson Disease Genomics Consortium, Nalls MA, Plagnol V, Hernandez DG, Sharma M, Sheerin UM, Saad M, Simón-Sánchez J, Schulte C, Lesage S, Sveinbjörnsdóttir S, Stefánsson K, Martinez M, Hardy J, Heutink P, Brice A, Gasser T, Singleton AB, Wood NW: Imputation of sequence variants for identification of genetic risks for Parkinson's disease: a meta-analysis of genome-wide association studies. Lancet 2011, 377:641-649.

5. Edwards TL, Scott WK, Almonte C, Burt A, Powell EH, Beecham GW, Wang L, Züchner S, Konidari I, Wang G, Singer C, Nahab F, Scott B, Stajich JM, Pericak-Vance M, Haines J, Vance JM, Martin ER: Genome-wide association study confirms SNPs in SNCA and the MAPT region as common risk factors for Parkinson disease. Ann Hum Genet 2010, 74:97-109.

6. Hamza TH, Zabetian CP, Tenesa A, Laederach A, Montimurro J, Yearout D, Kay DM, Doheny KF, Paschall J, Pugh E, et al: Common genetic variation in the HLA region is associated with late-onset sporadic Parkinson's disease. Nat Genet 2010, 42:781-785.

7. Saad M, Lesage S, Saint-Pierre A, Corvol JC, Zelenika D, Lambert JC, Vidailhet M, Mellick GD, Lohmann E, Durif F, Pollak P, Damier P, Tison F, Silburn PA, Tzourio C, Forlani S, Loriot MA, Giroud M, Helmer C, Portet F, Amouyel P, Lathrop M, Elbaz A, Durr A, Martinez M, Brice A, French Parkinson's Disease Genetics Study Group: Genome-wide association study confirms BST1 and suggests a locus on 12q24 as the risk loci for Parkinson's disease in the European population. Hum Mol Genet 2011, 20:615-627.

8. Simón-Sánchez J, van Hilten JJ, van de Warrenburg B, Post B, Berendse HW, Arepalli S, Hernandez DG, de Bie RM, Velseboer D, Scheffer H, Bloem B, van Dijk KD, Rivadeneira F, Hofman A, Uitterlinden AG, Rizzu P, Bochdanovits Z, Singleton $A B$, Heutink P: Genome-wide association study confirms extant PD risk loci among the Dutch. Eur J Hum Genet 2011, 19:655-661.

9. Paisán-Ruíz C, Jain S, Evans EW, Gilks WP, Simón J, van der Brug M, López de Munain A, Aparicio S, Gil AM, Khan N, Johnson J, Martinez JR, Nicholl D, Carrera IM, Pena AS, de Silva R, Lees A, Martí-Massó JF, Pérez-Tur J, Wood NW, Singleton $A B$ : Cloning of the gene containing mutations that cause PARK8-linked Parkinson's disease. Neuron 2004, 44:595-600. 
10. Zimprich A, Biskup S, Leitner $P$, Lichtner P, Farrer M, Lincoln S, Kachergus J, Hulihan M, Uitti RJ, Calne DB, Stoessl AJ, Pfeiffer RF, Patenge N, Carbajal IC, Vieregge P, Asmus F, Müller-Myhsok B, Dickson DW, Meitinger T, Strom TM, Wszolek ZK, Gasser T: Mutations in LRRK2 cause autosomal-dominant parkinsonism with pleomorphic pathology. Neuron 2004, 44:601-607.

11. Satake W, Nakabayashi Y, Mizuta I, Hirota Y, Ito C, Kubo M, Kawaguchi T, Tsunoda T, Watanabe M, Takeda A, Tomiyama H, Nakashima K, Hasegawa K, Obata F, Yoshikawa T, Kawakami H, Sakoda S, Yamamoto M, Hattori N, Murata M, Nakamura Y, Toda T: Genome-wide association study identifies common variants at four loci as genetic risk factors for Parkinson's disease. Nat Genet 2009, 41:1303-1307.

12. Greggio E, Cookson MR: Leucine-rich repeat kinase 2 mutations and Parkinson's disease: three questions. ASN Neuro 2009, 1:e00002.

13. Aasly JO, Vilariño-Güell C, Dachsel JC, Webber PJ, West AB, Haugarvoll K, Johansen KK, Toft M, Nutt JG, Payami H, Kachergus JM, Lincoln SJ, Felic A, Wider C, Soto-Ortolaza Al, Cobb SA, White LR, Ross OA, Farrer MJ: Novel pathogenic LRRK2 p.Asn1437His substitution in familial Parkinson's disease. Mov Disord 2010, 25:2156-2163.

14. Cookson MR: The role of leucine-rich repeat kinase 2 (LRRK2) in Parkinson's disease. Nat Rev Neurosci 2010, 11:791-797.

15. Haugarvoll K, Wszolek ZK: Clinical features of LRRK2 parkinsonism. Parkinsonism Relat Disord 2009, 15(Suppl 3):S205-S208.

16. Hulihan MM, Ishihara-Paul L, Kachergus J, Warren L, Amouri R, Elango R, Prinjha RK, Upmanyu R, Kefi M, Zouari M, Sassi SB, Yahmed SB, El EuchFayeche G, Matthews PM, Middleton LT, Gibson RA, Hentati F, Farrer MJ: LRRK2 Gly2019Ser penetrance in Arab-Berber patients from Tunisia: a case-control genetic study. Lancet Neurol 2008, 7:591-594.

17. Healy DG, Falchi M, O'Sullivan SS, Bonifati V, Durr A, Bressman S, Brice A, Aasly J, Zabetian CP, Goldwurm S, Ferreira JJ, Tolosa E, Kay DM, Klein C, Williams DR, Marras C, Lang AE, Wszolek ZK, Berciano J, Schapira AH, Lynch T, Bhatia KP, Gasser T, Lees AJ, Wood NW, International LRRK2 Consortium: Phenotype, genotype, and worldwide genetic penetrance of LRRK2-associated Parkinson's disease: a case-control study. Lancet Neurol 2008, 7:583-590.

18. Wszolek ZK, Vieregge P, Uitti RJ, Gasser T, Yasuhara O, McGeer P, Berry K, Calne DB, Vingerhoets FJ, Klein C, Pfeiffer RF: German-Canadian family (family A) with parkinsonism, amyotrophy, and dementia: longitudinal observations. Parkinsonism Relat Disord 1997, 3:125-139.

19. Hasegawa K, Stoessl AJ, Yokoyama T, Kowa H, Wszolek ZK, Yagishita S: Familial parkinsonism: study of original Sagamihara PARK8 (I2020T) kindred with variable clinicopathologic outcomes. Parkinsonism Relat Disord 2009, 15:300-306.

20. Liu M, Dobson B, Glicksman MA, Yue Z, Stein RL: Kinetic mechanistic studies of wild-type leucine-rich repeat kinase 2: characterization of the kinase and GTPase activities. Biochemistry 2010, 49:2008-2017.

21. Gasper R, Meyer S, Gotthardt K, Sirajuddin M, Wittinghofer A: It takes two to tango: regulation of $\mathrm{G}$ proteins by dimerization. Nat Rev Mol Cell Biol 2009, 10:423-429.

22. West AB, Moore DJ, Biskup S, Bugayenko A, Smith WW, Ross CA, Dawson VL, Dawson TM: Parkinson's disease-associated mutations in leucine-rich repeat kinase 2 augment kinase activity. Proc Natl Acad Sci USA 2005, 102:16842-16847.

23. Greggio E, Jain S, Kingsbury A, Bandopadhyay R, Lewis $P$, Kaganovich A, van der Brug MP, Beilina A, Blackinton J, Thomas KJ, Ahmad R, Miller DW, Kesavapany S, Singleton A, Lees A, Harvey RJ, Harvey K, Cookson MR: Kinase activity is required for the toxic effects of mutant $L R R K 2 /$ dardarin. Neurobiol Dis 2006, 23:329-341.

24. Taymans JM, Vancraenenbroeck R, Ollikainen P, Beilina A, Lobbestael E, De Maeyer M, Baekelandt V, Cookson MR: LRRK2 kinase activity is dependent on LRRK2 GTP binding capacity but independent of LRRK2 GTP binding. PLoS One 2011, 6:e23207.

25. Webber PJ, Smith AD, Sen S, Renfrow MB, Mobley JA, West AB: Autophosphorylation in the leucine-rich repeat kinase 2 (LRRK2) GTPase domain modifies kinase and GTP-binding activities. J Mol Biol 2011, 412:94-110.

26. Jaleel M, Nichols RJ, Deak M, Campbell DG, Gillardon F, Knebel A, Alessi DR: LRRK2 phosphorylates moesin at threonine-558: characterization of how Parkinson's disease mutants affect kinase activity. Biochem J 2007, 405:307-317.
27. Jorgensen ND, Peng Y, Ho CC, Rideout HJ, Petrey D, Liu P, Dauer WT: The WD40 domain is required for LRRK2 neurotoxicity. PLoS One 2009, 4: e8463.

28. MacLeod D, Dowman J, Hammond R, Leete T, Inoue K, Abeliovich A: The familial Parkinsonism gene $L R R K 2$ regulates neurite process morphology. Neuron 2006, 52:587-593.

29. Smith WW, Pei Z, Jiang H, Dawson VL, Dawson TM, Ross CA: Kinase activity of mutant LRRK2 mediates neuronal toxicity. Nat Neurosci 2006, 9:1231-1233.

30. Imai Y, Gehrke S, Wang HQ, Takahashi R, Hasegawa K, Oota E, Lu B: Phosphorylation of $4 \mathrm{E}-\mathrm{BP}$ by LRRK2 affects the maintenance of dopaminergic neurons in Drosophila. EMBO J 2008, 27:2432-2443.

31. Covy JP, Giasson BI: Identification of compounds that inhibit the kinase activity of leucine-rich repeat kinase 2. Biochem Biophys Res Commun 2009, 378:473-477

32. Anand VS, Reichling LJ, Lipinski K, Stochaj W, Duan W, Kelleher K, Pungaliya P, Brown EL, Reinhart PH, Somberg R, Hirst WD, Riddle SM, Braithwaite SP: Investigation of leucine-rich repeat kinase 2: enzymological properties and novel assays. FEBS J 2009, 276:466-478.

33. Lovitt B, Vanderporten EC, Sheng Z, Zhu H, Drummond J, Liu Y: Differential effects of divalent manganese and magnesium on the kinase activity of leucine-rich repeat kinase 2 (LRRK2). Biochemistry 2010, 49:3092-3100.

34. Kumar A, Greggio E, Beilina A, Kaganovich A, Chan D, Taymans JM, Wolozin B, Cookson MR: The Parkinson's disease associated LRRK2 exhibits weaker in vitro phosphorylation of $4 \mathrm{E}-\mathrm{BP}$ compared to autophosphorylation. PLoS One 2010, 5:e8730

35. Nichols RJ, Dzamko N, Morrice NA, Campbell DG, Deak M, Ordureau A, Macartney T, Tong Y, Shen J, Prescott AR, Alessi DR: 14-3-3 binding to LRRK2 is disrupted by multiple Parkinson's disease-associated mutations and regulates cytoplasmic localization. Biochem J 2010, 430:393-404.

36. Funayama M, Hasegawa K, Ohta E, Kawashima N, Komiyama M, Kowa H, Tsuji S, Obata F: An LRRK2 mutation as a cause for the parkinsonism in the original PARK8 family. Ann Neurol 2005, 57:918-921.

37. Ohta E, Hasegawa K, Gasser T, Obata F: Independent occurrence of I2020T mutation in the kinase domain of the leucine rich repeat kinase 2 gene in Japanese and German Parkinson's disease families. Neurosci Lett 2007, 417:21-23

38. Nuytemans K, Rademakers R, Theuns J, Pals P, Engelborghs S, Pickut B, de Pooter T, Peeters K, Mattheijssens M, Van den Broeck M, Cras P, De Deyn PP, van Broeckhoven C: Founder mutation p.R1441C in the leucinerich repeat kinase 2 gene in Belgian Parkinson's disease patients. Eur J Hum Genet 2008, 16:471-479.

39. Möller JC, Rissling I, Mylius V, Höft C, Eggert KM, Oertel WH: The prevalence of the G2019S and R1441C/G/H mutations in LRRK2 in German patients with Parkinson's disease. Eur J Neurol 2008, 15:743-745.

40. Mata IF, Cosentino C, Marca V, Torres L, Mazzetti P, Ortega O, Raggio V, Aljanati $R$, Buzó $R$, Yearout $D$, Dieguez E, Zabetian CP: LRRK2 mutations in patients with Parkinson's disease from Peru and Uruguay. Parkinsonism Relat Disord 2009, 15:370-373.

41. Mata IF, Hutter CM, González-Fernández MC, de Pancorbo MM, Lezcano E, Huerta C, Blazquez M, Ribacoba R, Guisasola LM, Salvador C, GómezEsteban JC, Zarranz JJ, Infante J, Jankovic J, Deng H, Edwards KL, Alvarez V, Zabetian CP: Lrrk2 R1441G-related Parkinson's disease: evidence of a common founding event in the seventh century in Northern Spain. Neurogenetics 2009, 10:347-353.

42. Criscuolo C, De Rosa A, Guacci A, Simons EJ, Breedveld GJ, Peluso S, Volpe G, Filla A, Oostra BA, Bonifati V, De Michele G: The LRRK2 R1441C mutation is more frequent than G2019S in Parkinson's disease patients from southern Italy. Mov Disord 2011, 26:1733-1736.

43. Khan NL, Jain S, Lynch JM, Pavese N, Abou-Sleiman P, Holton JL, Healy DG, Gilks WP, Sweeney MG, Ganguly M, Gibbons V, Gandhi S, Vaughan J, Eunson LH, Katzenschlager R, Gayton J, Lennox G, Revesz T, Nicholl D, Bhatia KP, Quinn N, Brooks D, Lees AJ, Davis MB, Piccini P, Singleton AB, Wood NW: Mutations in the gene LRRK2 encoding dardarin (PARK8) cause familial Parkinson's disease: clinical, pathological, olfactory and functional imaging and genetic data. Brain 2005, 128:2786-2796.

44. Lewis PA, Greggio E, Beilina A, Jain S, Baker A, Cookson MR: The R1441C mutation of LRRK2 disrupts GTP hydrolysis. Biochem Biophys Res Commun 2007, 357:668-671.

45. Li X, Tan YC, Poulose S, Olanow CW, Huang XY, Yue Z: Leucine-rich repeat kinase 2 (LRRK2)/PARK8 possesses GTPase activity that is altered in 
familial Parkinson's disease R1441C/G mutants. J Neurochem 2007, 103:238-247.

46. Daniëls V, Vancraenenbroeck R, Law BM, Greggio E, Lobbestael E, Gao F, De Maeyer M, Cookson MR, Harvey K, Baekelandt V, Taymans JM: Insight into the mode of action of the LRRK2 Y1699C pathogenic mutant. J Neurochem 2011, 116:304-315.

47. West AB, Moore DJ, Choi C, Andrabi SA, Li X, Dikeman D, Biskup S, Zhang Z, Lim KL, Dawson VL, Dawson TM: Parkinson's disease-associated mutations in LRRK2 link enhanced GTP-binding and kinase activities to neuronal toxicity. Hum Mol Genet 2007, 16:223-232.

48. Guo L, Gandhi PN, Wang W, Petersen RB, Wilson-Delfosse AL, Chen SG: The Parkinson's disease-associated protein, leucine-rich repeat kinase 2 (LRRK2), is an authentic GTPase that stimulates kinase activity. Exp Cell Res 2007, 313:3658-3670.

49. Li Y, Dunn L, Greggio E, Krumm B, Jackson GS, Cookson MR, Lewis PA, Deng J: The R1441C mutation alters the folding properties of the ROC domain of LRRK2. Biochim Biophys Acta 2009, 1792:1194-1197.

50. laccarino C, Crosio C, Vitale C, Sanna G, Carri MT, Barone P: Apoptotic mechanisms in mutant LRRK2-mediated cell death. Hum Mol Genet 2007, 16:1319-1326.

51. Lee BD, Shin JH, VanKampen J, Petrucelli L, West AB, Ko HS, Lee YI, Maguire-Zeiss KA, Bowers WJ, Federoff HJ, Dawson VL, Dawson TM: Inhibitors of leucine-rich repeat kinase-2 protect against models of Parkinson's disease. Nat Med 2010, 16:998-1000.

52. Dusonchet J, Kochubey O, Stafa K, Young SM Jr, Zufferey R, Moore DJ, Schneider BL, Aebischer P: A rat model of progressive nigral neurodegeneration induced by the Parkinson's disease-associated G2019S mutation in LRRK2. J Neurosci 2011, 31:907-912.

53. Plowey ED, Cherra SJ, Liu YJ, Chu CT: Role of autophagy in G2019SLRRK2-associated neurite shortening in differentiated SH-SY5Y cells. $J$ Neurochem 2008, 105:1048-1056.

54. Sämann J, Hegermann J, von Gromoff E, Eimer S, Baumeister R, Schmidt E: Caenorhabditis elegans LRK-1 and PINK-1 act antagonistically in stress response and neurite outgrowth. J Biol Chem 2009, 284:16482-16491.

55. Lin CH, Tsai PI, Wu RM, Chien CT: LRRK2 G2019S mutation induces dendrite degeneration through mislocalization and phosphorylation of $\tau$ by recruiting autoactivated GSK3 $\beta$. J Neurosci 2010, 30:13138-13149.

56. Winner B, Melrose HL, Zhao C, Hinkle KM, Yue M, Kent C, Braithwaite AT, Ogholikhan S, Aigner R, Winkler J, Farrer MJ, Gage FH: Adult neurogenesis and neurite outgrowth are impaired in LRRK2 G2019S mice. Neurobiol Dis 2011, 41:706-716.

57. Chan D, Citro A, Cordy JM, Shen GC, Wolozin B: Rac1 protein rescues neurite retraction caused by G2019S leucine-rich repeat kinase 2 (LRRK2). J Biol Chem 2011, 286:16140-16149.

58. Ramonet D, Daher JP, Lin BM, Stafa K, Kim J, Banerjee R, Westerlund M, Pletnikova O, Glauser L, Yang L, Liu Y, Swing DA, Beal MF, Troncoso JC, McCaffery JM, Jenkins NA, Copeland NG, Galter D, Thomas B, Lee MK, Dawson TM, Dawson VL, Moore DJ: Dopaminergic neuronal loss, reduced neurite complexity and autophagic abnormalities in transgenic mice expressing G2019S mutant LRRK2. PLoS One 2011, 6:e18568.

59. Dzamko N, Deak M, Hentati F, Reith AD, Prescott AR, Alessi DR, Nichols RJ: Inhibition of LRRK2 kinase activity leads to dephosphorylation of $\mathrm{Ser}^{910}$ / $\mathrm{Ser}^{935}$, disruption of 14-3-3 binding and altered cytoplasmic localization. Biochem J 2010, 430:405-413.

60. Liu Z, Hamamichi S, Dae Lee B, Yang D, Ray A, Caldwell GA, Caldwell KA, Dawson TM, Smith WW, Dawson VL: Inhibitors of LRRK2 kinase attenuate neurodegeneration and Parkinson-like phenotypes in Caenorhabditis elegans and Drosophila Parkinson's disease models. Hum Mol Genet 2011, 20:3933-3942.

61. Yun H, Heo HY, Kim HH, DooKim N, Seol W: Identification of chemicals to inhibit the kinase activity of leucine-rich repeat kinase 2 (LRRK2), a Parkinson's disease-associated protein. Bioorg Med Chem Lett 2011, 21:2953-2957.

62. Deng X, Dzamko N, Prescott A, Davies P, Liu Q, Yang Q, Lee JD, Patricelli MP, Nomanbhoy TK, Alessi DR, Gray NS: Characterization of a selective inhibitor of the Parkinson's disease kinase LRRK2. Nat Chem Biol 2011, 7:203-205

63. Ramsden N, Perrin J, Ren Z, Lee BD, Zinn N, Dawson VL, Tam D, Bova M, Lang M, Drewes G, Bantscheff M, Bard F, Dawson TM, Hopf C: Chemoproteomics-based design of potent LRRK2-selective lead compounds that attenuate Parkinson's disease-related toxicity in human neurons. ACS Chem Biol 2011, 6:1021-1028.

64. Chartier-Harlin MC, Dachsel JC, Vilariño-Güell C, Lincoln SJ, Leprêtre F, Hulihan MM, Kachergus J, Milnerwood AJ, Tapia L, Song MS, Le Rhun E, Mutez E, Larvor L, Duflot A, Vanbesien-Mailliot C, Kreisler A, Ross OA, Nishioka K, Soto-Ortolaza Al, Cobb SA, Melrose HL, Behrouz B, Keeling BH, Bacon JA, Hentati E, Williams L, Yanagiya A, Sonenberg N, Lockhart PJ, Zubair AC, et al: Translation initiator EIF4G1 mutations in familial Parkinson disease. Am J Hum Genet 2011, 89:398-406.

65. Tain LS, Mortiboys H, Tao RN, Ziviani E, Bandmann O, Whitworth AJ: Rapamycin activation of $4 \mathrm{E}-\mathrm{BP}$ prevents parkinsonian dopaminergic neuron loss. Nat Neurosci 2009, 12:1129-1135.

66. London N, Raveh B, Movshovitz-Attias D, Schueler-Furman O: Can selfinhibitory peptides be derived from the interfaces of globular proteinprotein interactions? Proteins 2010, 78:3140-3149.

67. Broglia RA, Provasi D, Vasile F, Ottolina G, Longhi R, Tiana G: A folding inhibitor of the HIV-1 protease. Proteins 2006, 62:928-933.

68. Li T, Yang D, Sushchky S, Liu Z, Smith WW: Models for LRRK2-linked parkinsonism. Parkinsons Dis 2011, 2011:942412.

69. Herzig MC, Kolly C, Persohn E, Theil D, Schweizer T, Hafner T, Stemmelen C, Troxler TJ, Schmid P, Danner S, Schnell CR, Mueller M, Kinzel B, Grevot A, Bolognani F, Stirn M, Kuhn RR, Kaupmann K, van der Putten PH, Rovelli G, Shimshek DR: LRRK2 protein levels are determined by kinase function and are crucial for kidney and lung homeostasis in mice. Hum Mol Genet 2011, 20:4209-4223.

70. Tong Y, Yamaguchi H, Giaime E, Boyle S, Kopan R, Kelleher RJ, Shen J: Loss of leucine-rich repeat kinase 2 causes impairment of protein degradation pathways, accumulation of a-synuclein, and apoptotic cell death in aged mice. Proc Natl Acad Sci USA 2010, 107:9879-9884.

71. Davis MI, Hunt JP, Herrgard S, Ciceri P, Wodicka LM, Pallares G, Hocker M, Treiber DK, Zarrinkar PP: Comprehensive analysis of kinase inhibitor selectivity. Nat Biotechnol 2011, 29:1046-1051.

72. Saunders-Pullman R, Barrett MJ, Stanley KM, Luciano MS, Shanker V, Severt L, Hunt A, Raymond D, Ozelius LJ, Bressman SB: LRRK2 G2019S mutations are associated with an increased cancer risk in Parkinson disease. Mov Disord 2010, 25:2536-2541.

73. Pan T, Li X, Jankovic J: The association between Parkinson's disease and melanoma. Int J Cancer 2011, 128:2251-2260.

\section{Pre-publication history}

The pre-publication history for this paper can be accessed here: http://www.biomedcentral.com/1741-7015/10/20/prepub

doi:10.1186/1741-7015-10-20

Cite this article as: Rudenko et al:: Is inhibition of kinase activity the only therapeutic strategy for LRRK2-associated Parkinson's disease? BMC Medicine 2012 10:20.

\section{Submit your next manuscript to BioMed Central and take full advantage of:}

- Convenient online submission

- Thorough peer review

- No space constraints or color figure charges

- Immediate publication on acceptance

- Inclusion in PubMed, CAS, Scopus and Google Scholar

- Research which is freely available for redistribution

Submit your manuscript at www.biomedcentral.com/submit
C Biomed Central 